\title{
O DISCURSO CANADENSE DO MULTICULTURALISMO NO DISCURSO DOS DIREITOS HUMANOS: INTEGRAR OU ASSIMILAR?
}

\author{
DIEGO BARBOSA DA SILVA ${ }^{1}$ \\ Arquivo Nacional. Praça da República, 173 - Centro - Rio de Janeiro - RJ - Brasil \\ vsjd@uol.com.br, diego@an.com.br
}

\begin{abstract}
Resumo. Atualmente, o Canadá se constrói no mito de uma terra hospitaleira, tolerante e próspera, que garantirá recursos econômicos e direitos sociais de forma igualitária para as mais variadas culturas. Neste artigo, por meio do aparato teórico-metodológico de Pêcheux e Orlandi, dando continuidade à análise do funcionamento do discurso do multiculturalismo nesse país, observamos movimentos de sentido de uma política de assimilação da diferença para uma política de integração da diferença. Contudo, mostramos que para se tornar dominante, o discurso do multiculturalismo se ancora no discurso dos direitos humanos, ampliando sua capacidade de dissimulação para encobrir uma memória da assimilação que permanece.
\end{abstract}

Palavras-chave: discurso; multiculturalismo; direitos humanos; Canadá.

\begin{abstract}
Today, Canada builds on the myth of a hospitable land, tolerant and prosperous land that will guarantee economic resources and social rights in an equal way for the most diverse cultures. In this article, through the theoretical-methodological apparatus of Pêcheux and Orlandi, giving continuity to the analysis of the multiculturalism discourse in that country, we observe movements of meaning of a policy of assimilation of difference into a policy of integration of difference. However, we have shown that to become dominant, the discourse of multiculturalism is anchored in the discourse of human rights, expanding its capacity for dissimulation to cover up a memory of the assimilation that remains.
\end{abstract}

Keywords: discourse; multiculturalism; human rights; Canada.

Em outra oportunidade (BARBOSA DA SILVA, 2018) analisando a emergência do discurso do multiculturalismo no Canadá nos anos 1960 e 1970, observamos que, no discurso sociológico sobre o sentido de cultura, o discurso do multiculturalismo emerge por meio de formas de deslocamentos em que a sociedade canadense passaria de monocultural para bicultural e depois multicultural e, uma vez alcançado esse sentido de sociedade de várias culturas, a política adotada pelo Estado deveria denominar-se multiculturalismo, no Canadá, e interculturalismo, no Quebec, trazendo consigo as memórias de outros ismos. A análise de tais movimentos expõe uma contradição quando se observa a política linguística, que se mantém bilíngue no Canadá, um país

1 Doutor em Estudos de Linguagem pela UFF. Pesquisador do Arquivo Nacional do Brasil. Ex-DiretorGeral da instituição e Ex-Presidente do Conselho Nacional de Arquivos. 
multicultural, e se mantém monolíngue no Quebec, um estado intercultural, negando a possibilidade do multilinguismo em ambos. Analisamos também como a emergência do discurso do multiculturalismo no Canadá fundou uma outra discursividade sobre a origem do país: a do encontro de três povos: francês, inglês e aborígene, encobrindo ou mesmo silenciando a dominação europeia sobre a diferença. Somente sobre essa outra discursividade que foi possível erguer o mito do Canadá como uma terra próspera e hospitaleira destinada a receber imigrantes do mundo todo das mais variadas culturas. Neste artigo, continuamos nossa análise em torno do discurso do multiculturalismo no Canadá por meio do aparato teórico-metodológico de Pêcheux e Orlandi.

Pierre Trudeau, primeiro-ministro de 1968 a 1979 e de 1980 a 1984, eleito pelo Partido Liberal, seguindo as recomendações posteriores da Royal Commission on Bilingualism and Biculturalism/Commission royale d'enquête sur le bilinguisme et le biculturalisme $^{2}$, foi ao Parlamento, no dia 8 de outubro de 1971 e apresentou uma mudança de política, do biculturalismo para o multiculturalismo. Nessa mesma ocasião, Trudeau também enunciava uma mudança de política no governo canadense da política de assimilação para a política de integração. Da posição do sociólogo, a diferença entre elas se daria no modo como um membro de uma cultura distinta deveria ser e se comportar para pertencer à sociedade canadense e nela ser aceito. Enquanto, na assimilação, o imigrante ou o indígena deveriam abandonar todas as suas práticas culturais, identificando e se assujeitando à cultura canadense, na integração, eles poderiam manter as suas culturas ao participar da sociedade canadense desde que fosse possível uma conciliação ${ }^{3}$. Na assimilação, diferentemente da integração, os imigrantes e indígenas por mais "estranhos, extemporâneos e atrasados" seriam, assim, "evoluíveis, educáveis e consertáveis" (CAVALCANTI; SIMÕES, 2013).

Sob a política de assimilação, no Canadá, durante a colonização europeia, os indígenas foram obrigados a adotar o Cristianismo, a agricultura e o sedentarismo, abandonando suas práticas de caça e pesca. Durante a I e a II Guerras Mundiais, respectivamente, ucranianos foram levados para campos de trabalho forçado e japoneses tiveram seus bens confiscados pelo Estado canadense (CANADÁ, 2012, p. 21 e 23). Até os anos 1960, o país selecionava preferencialmente imigrantes brancos europeus e impunha restrições à entrada de asiáticos, negros estadunidenses, africanos e latinoamericanos (ESTEBAN; LÓPEZ-SALA, 2010, p. 662). Além disso, os imigrantes brancos não britânicos deveriam adotar a cultura britânica ou francesa, e o indígena só poderia ter os mesmos direitos dos não indígenas, como votar nas eleições federais, se renunciasse à sua condição de índio (OLIVERAS, 2001, p. 244). Até os anos 1980, mesmo após a adoção pelo governo de medidas políticas em prol das mais variadas culturas, isto é, quando se afirmava a adoção da política de integração, línguas e práticas culturais indígenas eram proibidas; crianças eram retiradas de suas famílias e povos para serem criadas por canadenses de origem europeia ou levadas para escolas ocidentais, onde

\footnotetext{
2 A Bi and Bi Commission (1963-1969), como também é chamada, foi criada com a intenção de reconhecer a igualdade de direitos de canadenses francofalantes frente aos anglofalantes, durante a Révolution Tranquille. Primeiramente a Royal Commission defendeu que, oficialmente, o Canadá se tornasse um país bilíngue, posteriormente, foi favorável a que o país adotasse o multiculturalismo como política oficial (RATTANSI, 2011, p. 8).

${ }^{3}$ Esse processo de mudança de uma política de assimilação para uma de integração dos povos indígenas ocorreu em todo o mundo na segunda metade do século XX, inclusive no Brasil, onde o Estatuto do Indio, de 1973 - em consonância com a Convenção 107, de 1957, da Organização Internacional do Trabalho - no seu artigo $4^{\circ}$ considera os índios como a) isolados, b) em vias de integração e c) integrados, "quando incorporados à comunhão nacional e reconhecidos no pleno exercício dos direitos civis, ainda que conservem usos, costumes e tradições característicos da sua cultura".
} 
sofriam maus tratos. Ademais, até essa data, o governo decidia quem era ou não índio e quando se perdia esse status que tinha como consequência a perda do direito à propriedade de terra ${ }^{4}$, como por exemplo, quando uma mulher indígena se casava com um homem não indígena (CANADÁ, 2015) .

Com a emergência do discurso do multiculturalismo, não era mais possível manter uma política de assimilação centrada em uma ou duas culturas nacionais e oficiais. E isso pode ser observado no próprio pronunciamento de Trudeau:

SD1.1: The government accepts and endorses the recommendations and spirit of Book IV of the Royal Commission on Bilingualism and Biculturalism. It believes the time is overdue for the people of Canada to become more aware of the rich tradition of the many cultures we have in Canada. Canada's citizens come from almost every country in the world, and bring with them every major world religion and language. This cultural diversity endows all Canadians with a great variety of human experience. The government regards this as a heritage to treasure and believes that Canada would be the poorer if we adopted assimilation programs forcing our citizens to forsake and forget the cultures they have brought to us (TRUDEAU, 1971; grifos nossos) ${ }^{6}$

Com o reconhecimento do Canadá como um país com muitas culturas "vindas de quase todos os países do mundo", multicultural, as outras culturas, diferentes, que antes eram da ordem do erro, passaram a ser vistas como parte da herança, do patrimônio canadense na política de integração. Tal modificação não significaria, no entanto, uma ausência de conflito. Afinal, podemos observar que, mesmo com a política de integração, as tensões provocadas pelas mais variadas culturas não foram apagadas completamente, sendo inclusive afirmada nos relatórios anuais sobre o multiculturalismo, instituídos pelo Canadian Multiculturalism Act em 1988:

SD2.1: But multiculturalism is not simply a government program: it is the day-today reality of our country, in which Canadians of very different origins live and work side by side, in which new Canadians work hard to learn our languages, our values, and our traditions, and, in turn, are welcomed as equal members of the Canadian family. Canada's peaceful pluralism, which is the envy of so many nations, depends on that welcoming community spirit being multiplied across the country. For generations, multiculturalism has been a path to integration of newcomers from around the world. It has helped Canadians, regardless of origin or beliefs, to contribute to furthering the growth and prosperity of their new country. Multiculturalism has become a shared value that encourages new Canadians to maintain those family, religious, and cultural traditions that are consistent with Canadian values such as

\footnotetext{
${ }^{4}$ Durante os anos 1960, a Funai, no Brasil, também atribuía o status político de indígena apenas àqueles que falavam alguma língua indígena (OLIVEIRA, 2004).

${ }^{5}$ Somente em 2008, o governo federal canadense pediu desculpas aos povos autóctones pela política de assimilação.

${ }^{6}$ Tradução nossa: "SD1.1: O governo aceita e endossa as recomendações e o espírito do Livro IV da Royal Commission on Bilingualism and Biculturalism. Ele acredita que já passou o tempo do povo canadense se tornar mais consciente da rica tradição das muitas culturas que temos no Canadá. Os cidadãos canadenses vêm de quase todos os países do mundo, e trazem com eles todas as grandes religiões e línguas do mundo. Esta diversidade cultural dota todos os canadenses com uma grande variedade de experiência humana. $O$ governo considera que essa é uma rica herança e acredita que o Canadá seria mais pobre se nós adotássemos programas de assimilação forçando nossos cidadãos a abandonarem e a esquecerem as culturas que trouxeram para nós".
} 
human dignity and equality before the law. (Relatório 2011/2012, p. 8; grifos nossos) ${ }^{7}$

SD2.2: Although Canadian society is generally cohesive, challenges remain. These include tensions over the "reasonable accommodation" of cultural and religious traditions; the persistence of racism and discrimination; marginalization and exclusion, which can result in poverty, as well as potentially foster extremism; limited socio-economic integration and opportunities for certain Canadians; and declining civic participation and an overall lack of knowledge of our history and political institutions. (Relatório 2010/2011, p. 12; grifos nossos) ${ }^{8}$

$\mathrm{Na}$ primeira sequência, o multiculturalismo não é apenas um programa de governo, é algo posto, que faz parte da história e do patrimônio canadense. É um valor da sociedade por meio do qual os imigrantes vindos do mundo todo podem nela se incluir mantendo a sua religião e a sua língua de forma pacífica (SD2.1). Nessas sequências, a $\mathrm{SD} 2.1$ e a SD2.2, encontramos também marcas das tensões que ocorrem em um ambiente culturalmente variado, como racismo, discriminação, marginalização, exclusão, desigualdade social, extremismo, dificuldades de integração e de aprender os idiomas oficiais. Ainda assim, mesmo que não silenciadas no fio discursivo, essas tensões poderiam ser superadas pelo multiculturalismo, posto como pacificador, bastando que todos o aceitassem como um valor para manter suas tradições e religiões de origem desde que conciliadas com os valores canadenses ${ }^{9}$. Ao se reconhecer a existência de problemas relacionados ao contato de diferentes culturas, de certa forma se dissimula melhor a evidência do multiculturalismo como algo positivo, afinal ele seria capaz de dar respostas e resolver os problemas causados pelo contato de diferentes povos no Canadá, deslocando a política de assimilação para uma política de integração.

Orlandi (2007 [1999], p. 32) nos mostra que "as palavras não são nossas. Elas significam pela história e pela língua. O que é dito em outro lugar também significa nas 'nossas' palavras. O sujeito diz, pensa que sabe o que diz, mas não tem acesso ou controle sobre o modo pelo qual os sentidos se constituem nele". Assim, como não há discurso sem memória, a memória da política de integração decorre da memória da política de assimilação. O que estamos querendo dizer é que é impossível pensar nos sentidos de integração sem considerar os sentidos de assimilação, seja pelo não dito ou pela falha,

7 Tradução nossa : "SD2.1: Mas o multiculturalismo não é simplesmente um programa de governo: é a realidade do dia-a-dia do nosso país, em que os canadenses de origens muito diferentes vivem e trabalham lado a lado, em que novos canadenses trabalham duro para aprender nossas línguas, nossos valores, e as nossas tradições e, por sua vez, são recebidos como membros iguais da família canadense. O pluralismo pacífico do Canadá, que é a invejado por tantas nações, depende do espírito de boas-vindas da comunidade que está sendo multiplicado em todo o país. Por gerações, o multiculturalismo tem sido um caminho para a integração dos recém-chegados de todo o mundo. Ele tem ajudado os canadenses, independentemente da origem ou crenças, a contribuir para promover o crescimento e a prosperidade do seu novo país. $O$ multiculturalismo tornou-se um valor compartilhado, que incentiva novos canadenses a manter essas famílias e as tradições culturais religiosas que são consistentes com os valores canadenses, tais como a dignidade humana e a igualdade perante a lei".

8 Tradução nossa: "SD2.2: Embora a sociedade canadense seja coesa de forma geral, os desafios permanecem. Esses incluem tensões relacionadas à "acomodação razoável" das tradições culturais e religiosas; à persistência do racismo e da discriminação; à marginalização e exclusão, ao que pode resultar em uma situação de pobreza, bem como potencialmente fomentar o extremismo; à integração sócioeconômica limitada e a oportunidades apenas para determinados canadenses; e ao declínio da participação cívica e uma total falta de conhecimento da nossa história e instituições políticas".

${ }^{9}$ Kymlicka (2014 [2012], p. 126) afirma, inclusive, que a política de integração das diferentes culturas na sociedade funciona melhor quanto maior for a variedade de culturas. Assim, quanto maior a variedade cultural, maiores as chances de aceitarem as duas línguas e valores ocidentais canadenses, inclusive como meio de interagirem entre si. Melhor seria, desse modo, exercido o controle do sujeito pelo Estado. 
algo se mantém nesse processo de integração como mostraremos a partir de agora.

Retornando ao pronunciamento de Trudeau no Parlamento, em 1971, notamos inicialmente isso no modo de dizer a quem essa política multicultural estaria destinada. Nesse texto, percebemos que toda vez que se enunciam os grupos étnicos e culturais do Canadá, há o acompanhamento, logo a seguir, de uma relativa, como nas sequências discursivas abaixo, com itálicos nossos.

SD3.1: The government will support and encourage the various cultures and ethnic groups that give structure and vitality to our society. They will be encouraged to share their cultural expression and values with other Canadians and so contribute to a richer life for us all. (TRUDEAU, 1971) ${ }^{10}$

SD3.2: First, resources permitting, the government will seek to assist all Canadian cultural groups that have demonstrated a desire and effort to continue to develop a capacity to grow and contribute to Canada, and a clear need for assistance, the small and weak groups no less than the strong and highly organized. (TRUDEAU, 1971) ${ }^{11}$

De acordo com a Collins Cobuild English Grammar (1994, p. 362-373) e com Swan (2002, p. 487-497), na língua inglesa, há dois tipos de orações relativas: a) identifying, defining or restrictive relative clause, ou relativa restritiva, em português e b) non-identifying, non-defining or non-restrictive relative clause, ou relativa explicativa, em português. A diferença é que uma, no caso, a primeira, identifica ou classifica os nomes, enquanto a outra não. O modo de distingui-las se dá, como em português, por meio de uma pausa ou entonação na fala e por meio da pontuação, na escrita. A identifying relative clause não apresenta vírgula ou pausa, e a non-identifying relative clause apresenta. Além disso, o uso do pronome that é restrito para as identifying relative clauses, não sendo usual para as non-identifying relative clauses. Desse modo, analisando as sequências the various cultures and ethnic groups that give structure and vitality to our society e all Canadian cultural groups that have demonstrated, pode parecer transparente - sob uma abordagem puramente gramatical - que, pela ausência de vírgula e pelo uso do pronome that, se trata da identifying relative clause, isto é, da relativa restritiva, significando que o governo do país incentivará apenas os grupos que dão estrutura e vitalidade para a sociedade canadense.

Ainda que, como vimos, tal oração seja uma relativa restritiva, a possível ambiguidade de dizer que todos os grupos dão estrutura e vitalidade para a sociedade canadense - como relativa explicativa -, ou apenas alguns - como relativa restritiva -, não é desfeita pelo uso da pausa ou pelo uso da vírgula, pois não se refere apenas à base linguística.

Para Pêcheux (2011), essa ambiguidade - das subordinadas adjetivas - não é propriamente linguística, mas, sim, discursiva, sendo uma manifestação ideológica no interior do funcionamento da língua. De acordo com ele, esse efeito discursivo existe "nos discursos socialdemocratas ou de extrema-esquerda; e ele se manifesta mais fortemente

\footnotetext{
10 Tradução nossa: "SD3.1: O governo irá apoiar e incentivar as diversas culturas e grupos étnicos (,) que dão estrutura e vitalidade para a nossa sociedade. Eles serão incentivados a partilhar a sua expressão cultural e valores com outros canadenses e assim contribuir para uma vida mais rica para todos nós".

11 Tradução nossa: "SD3.2: Primeiro, se os recursos permitirem, o governo deverá ajudar todos os grupos culturais canadenses (,) que têm demonstrado um desejo e esforço para continuar a desenvolver a capacidade de crescer e contribuir para o Canadá, e uma clara necessidade de intervenção, os grupos pequenos e fracos não menos do que os fortes e altamente organizados".
} 
no funcionamento dos discursos da burguesia dirigente que, através dos meios de comunicação de massa, utiliza conscientemente esse tipo de ambiguidade" (PÊCHEUX, 2011, p. 137). Tal ambiguidade, ao mesmo tempo em que é marca da contradição discursiva, permite ao governo de Trudeau a interpretação de que as políticas multiculturais se destinam a todos, no caso da explicativa, como apenas a alguns, no caso da restritiva. Isso possibilita interpelar o maior número possível de sujeitos no Canadá, inclusive, sob gestos opostos de interpretação, dissimulando, "na transparência do sentido que nela se forma (em qualquer das interpretações), a objetividade material contraditória do interdiscursivo" (PÊCHEUX, 2009 [1975], p. 149).

Além disso, refletindo ainda sobre a tensão entre os efeitos de sentido de política de assimilação e de política de integração, retornando ao nosso gesto de interpretação dos relatórios anuais sobre o multiculturalismo e da publicação Discover Canada ${ }^{12}$, lemos que, de acordo com a legislação canadense (CANADÁ, 2015), qualquer pessoa pode imigrar para o país desde que atenda os pré-requisitos atualmente exigidos e seja aprovada no processo de recrutamento do governo: ter idade mínima de 18 anos; ter diploma de nível superior; ter experiência de trabalho de pelo menos um ano; ter proficiência em uma das duas línguas oficiais do país, inglês ou francês. É o governo que define quem será aceito na sociedade canadense e aqueles que driblarem essas regras e entrarem no país de forma "ilegal e desonesta", quando descobertos, tendem a ser rejeitados pela sociedade por causa do seu "comportamento" (KYMLICKA, 2014 [2012], p. 155).

Já para se tornar cidadão exige-se, além dos mesmos pré-requisitos para 0 imigrante, ter residido no Canadá por pelo menos três anos nos últimos quatro; ter conhecimento sobre a história, a política, a geografia e a legislação canadenses, comprovado em um teste ${ }^{13}$; não ter antecedentes criminais e aceitar os valores da sociedade canadense (CANADÁ, 2015), que repudiam alguns comportamentos, como podemos observar na sequência a seguir, com grifos nossos em itálico:

SD4.1: In Canada, men and women are equal under the law. Canada's openness and generosity do not extend to barbaric cultural practices that tolerate spousal abuse, "honour killings," female genital mutilation, forced marriage or other gender-based violence. Those guilty of these crimes are severely punished under Canada's criminal laws. (DISCOVER CANADA, 2012, p. 9) ${ }^{14}$

Uma vez concedida a autorização para a aquisição da cidadania, o candidato deve participar da cerimônia de juramento ao soberano britânico, afinal, como se sabe, o Canadá, mesmo independente, ainda é uma monarquia, cujo chefe de Estado é o monarca

\footnotetext{
12 A publicação Discover Canada: The Rights and Responsibilities of Citizenship (2012) é organizada pelo Department of Citizenship and Immigration, o Ministério de Cidadania e Imigração do Canadá com a finalidade de servir como material de estudo para o teste de cidadania a ser realizado por aqueles que desejam se tornar canadenses.

${ }^{13}$ Entre as muitas etapas para se tornar cidadão canadense está o teste de cidadania em que o candidato deve responder questões sobre política, geografia e história do país para ser aprovado. Quando se inscreve para o teste, o candidato recebe em sua residência uma cópia impressa do Discover Canada. Desse modo, para se tornar cidadão canadense, o candidato deve ser interpelado como um "bom sujeito", ou seja, realizando seu assujeitamento "sob a forma do livre consentimento" (PÊCHEUX, 2009 [1975], p. 215), assujeitando-se às formações discursivas contidas no manual.

14 Tradução nossa: "SD4.1: No Canadá, homens e mulheres são iguais perante a lei. A abertura e generosidade do Canadá não se estendem a práticas culturais bárbaras que toleram o abuso conjugal, "crimes de honra", a mutilação genital feminina, os casamentos forçados ou outra violência baseada no gênero. Os culpados destes crimes são severamente punidos nos termos da legislação penal do Canadá".
} 
britânico, como na Austrália e na Nova Zelândia.

SD4.2: Understanding the Oath

In Canada, we profess our loyalty to a person who represents all Canadians and not to a document such as a constitution, a banner such as a flag, or a geopolitical entity such as a country. In our constitutional monarchy, these elements are encompassed by the Sovereign (Queen or King). It is a remarkably simple yet powerful principle: Canada is personified by the Sovereign just as the Sovereign is personified by Canada (DISCOVER CANADA, 2012, p. 2; grifos nossos) ${ }^{15}$

Ainda que se construa a evidência, inclusive, por meio do mito canadense de terra hospitaleira de que o multiculturalismo é uma política de integração, contrária à de assimilação, como vimos, nos fragmentos anteriores, observamos que o país parece não estar aberto à diferença como se afirma. No país, não apenas se consideram como bárbaras algumas práticas culturais distintas da cultura canadense - que se inscrevem na memória do colonizador europeu - como também só aceitariam sujeitos imigrantes que abandonassem tais práticas contrárias aos valores ocidentais e aos direitos humanos. Como exemplos dessas práticas, estariam a mutilação genital feminina (SD4.1), comum em alguns países africanos e questões de gênero e de sexualidade (SD4.1), entre elas a homossexualidade, cuja aceitação, de 1978 a 2002, de acordo com o Immigration Act (CANADÁ, 1976), era facultativa para cada província do país ${ }^{16}$. Além disso, devem passar pelo ritual do juramento ao soberano inglês, simbolizando o seu compromisso com os valores ocidentais da sociedade canadense e o seu assujeitamento a eles. Haveria, assim, um movimento parafrástico entre política de integração e política de assimilação, "uma diferente formulação do mesmo dizer sedimentado" (ORLANDI, 2007 [1999], p. $36)$.

Para Kymlicka (2014 [2012], p. 126 e 131), o Canadá multiculturalista rejeitará aqueles "incapazes ou não dispostos" a aceitar os direitos humanos:

para essas pessoas, o multiculturalismo oferece tanto oportunidades quanto desafios [...]. No entanto, há um preço para esse acesso: aceitar os princípios dos direitos humanos e liberdades civis e os procedimentos do constitucionalismo democrático liberal, com suas garantias de igualdade de gênero, liberdade religiosa, não discriminação racial, direitos dos homossexuais, processo devido, e assim, por diante (grifos nossos).

Isso ocorre, segundo ele, justamente porque o multiculturalismo "é parte de uma revolução maior por direitos humanos, envolvendo diversidade étnica e racial" (KYMLICKA, 2014 [2012], p. 136), após a II Guerra Mundial. E tais exigências estariam de acordo com outras democracias ocidentais, afinal, para Kymlicka, nenhuma delas isentou os imigrantes do cumprimento das normas de direitos humanos.

Na publicação Discover Canada (2012), ainda é possível observar a importância

\footnotetext{
15 Tradução nossa: "SD4.2: Compreendendo o Juramento. No Canadá, nós professamos a nossa lealdade a uma pessoa que representa todos os canadenses e não a um documento, como uma constituição, como um estandarte, como uma bandeira, ou uma entidade geopolítica, como um país. Em nossa monarquia constitucional, estes elementos são abrangidos pelo Soberano (Rainha ou Rei). E um princípio bem simples, mas poderoso: o Canadá é personificado no Soberano assim como o Soberano é personificado no Canadá". 16 Nesse mesmo período, o Immigration Act também facultava às províncias a aceitação ou não de imigrantes deficientes físicos (CANADÁ, 1976).
} 
dada à religião cristã, bem como à dignidade da pessoa humana, retomando a memória do discurso (da formação discursiva) dos direitos humanos. Pêcheux (2009 [1975], p. 147) considera uma formação discursiva a partir das ideias de Althusser (1985 [1970]) como aquilo "que pode e deve ser dito [...] a partir de uma posição dada na conjuntura social", aquilo que pode e deve ser dito no discurso dos direitos humanos. Vejamos as sequências com grifos nossos.

SD4.3: The Constitution of Canada was amended in 1982 to entrench the Canadian Charter of Rights and Freedoms, which begins with the words, "Whereas Canada is founded upon principles that recognize the supremacy of God and the rule of law." This phrase underlines the importance of religious traditions to Canadian society and the dignity and worth of the human person. (DISCOVER CANADA, 2012, p. 8) ${ }^{17}$ SD4.4: Together, these (rights and freedoms) secure for Canadians an 800 -year old tradition of ordered liberty, which dates back to the signing of Magna Carta in 1215 in England (also known as the Great Charter of Freedoms). (DISCOVER CANADA, 2012, p. 8) ${ }^{18}$

De acordo com Orlandi (2007 [1999], p. 39), "não há discurso que não se relacione com outros. Em outras palavras, os sentidos resultam de relações: um discurso aponta para outros que o sustentam". Podemos, então, afirmar que, no Canadá, o discurso do multiculturalismo se sustenta no discurso dos direitos humanos e isso se evidencia, inclusive, quando o discurso do multiculturalismo é ameaçado ou atacado ${ }^{19}$. Desse modo, o silenciamento da diferença, contrária aos valores ocidentais, que antes era feito por meio de aparelhos repressores de Estado (ALTHUSSER, 1985 [1970]), baseada na política de assimilação, é feito, atualmente na política de integração de forma dissimulada por meio do discurso do multiculturalismo que se ancora na Formação Discursiva dos Direitos Humanos em que, sob a projeção e a ilusão de um sujeito universal, se esquecem a historicidade desse discurso e suas relações históricas e sociais no/com o continente europeu, bem como as condições de produção para a sua emergência na Europa pósHolocausto.

Como se não bastasse, por fim, além de aceitar os valores canadenses, para participar dessa sociedade, o indivíduo de outra cultura, ainda que possa manter a sua língua materna no espaço privado ${ }^{20}$, deve adquirir uma das línguas oficiais, mas de preferência as duas, sendo que no Quebec, com sua política intercultural e monolíngue, só é possível se integrar pela aquisição do francês. Isso pode ser visto nessas duas sequências, com grifos nossos, retiradas do panfleto "Conhecer, respeitar, partilhar: valores em comum da sociedade quebequense", o mesmo de onde retiramos o enunciado uma terra hospitaleira, publicado em seis línguas, entre elas o português, para informar

\footnotetext{
17 Tradução nossa: "SD4.3: A Constituição do Canadá foi alterada, em 1982, para consolidar a Carta Canadense de Direitos e Liberdades, que começa com as palavras: 'Considerando que o Canadá é fundado em princípios que reconhecem a supremacia de Deus e do Estado de Direito'. Esta frase sublinha a importância de tradições religiosas para a sociedade canadense e a dignidade e o valor da pessoa humana. 18 Tradução nossa: "SD4.4: Juntos, esses (direitos e liberdades) garantiram para os canadenses uma tradição de 800 anos de liberdade ordenada, que remonta à assinatura da Magna Carta em 1215 na Inglaterra (também conhecida como a Grande Carta das Liberdades)".

${ }^{19}$ Kymlicka (2014 [2012]) escreveu esse artigo no qual defende o multiculturalismo a partir dos direitos humanos, em 2012, de acordo com o próprio autor, como uma resposta aos governantes europeus, que tinham afirmado que o multiculturalismo fracassou.

${ }^{20}$ Na posição de sociólogo, Kymlicka (2014 [2012], p. 140) afirma que os imigrantes vão se integrar mais facilmente se perceberem que as suas culturas são respeitadas, como por exemplo, as suas línguas maternas na esfera privada. Ou seja, o próprio direito de falar a língua materna também faz parte do processo de integração.
} 
aqueles que desejam imigrar para o Quebec:

SD4.5: VALORES A SEREM PARTILHADOS Quebec, terra hospitaleira de muitos imigrantes vindos do mundo todo, é uma sociedade fundamentada em valores em comum que modelam sua própria identidade. A língua francesa é a expressão desse aspecto, além de ser a língua oficial do Quebec. Viver no Quebec é viver em francês. (QUEBEC, 2009; grifos nossos em itálico)

SD4.6: No Quebec, FALAR FRANCÊS É UMA NECESSIDADE A sociedade quebequense é regida pela Charte de la langue française [Carta da Língua Francesa] que estabelece o francês como língua oficial do Quebec. O francês é a língua dos órgãos públicos e a língua utilizada correntemente no trabalho, no ensino, nas comunicações, no comércio e no mundo dos negócios. Quebec empenha-se em preservar e promover sua língua oficial. A língua francesa é, não apenas um instrumento de comunicação essencial, mas também um símbolo em comum de pertencimento à sociedade quebequense. Para se integrar ao seu novo ambiente de vida, os imigrantes que não dominam a língua francesa devem esforçar-se para aprendê-la. Para ajudá-los nesse sentido, o governo do Quebec oferece-lhes cursos de francês. Os filhos dos imigrantes estabelecidos permanentemente no Quebec frequentam o ensino regular que é ministrado em francês. As candidatas e os candidatos ao exercício de uma profissão regida por uma ordem profissional devem demonstrar ter o conhecimento suficiente da língua francesa para poder, então, conseguir uma credencial regularizada de suas respectivas ordens. (QUEBEC, 2009; grifos nossos em itálico)

Nessas duas sequências, percebemos a importância da língua francesa para o Quebec. O francês é muito mais que um meio de comunicação ou uma utilidade para a administração pública, ele é posto como símbolo em comum de pertencimento à sociedade quebequense (SD4.6). Sendo assim, viver no Quebec é viver em francês (SD4.5) e falar francês é uma necessidade, não uma opção (SD4.6) Não existe, portanto, a opção de se viver no Quebec sem ter conhecimentos de francês. Os estrangeiros, candidatos a um emprego devem conhecer a língua, e os imigrantes que não a dominam devem se esforçar para aprendê-la (SD4.6), podendo, inclusive fazer um dos cursos oferecidos pelo governo.

Desse modo, para o governo quebequense, a integração ao Estado só é possível por meio do aprendizado da língua francesa. A língua ganha o sentido de algo possível de ser adquirido e torna-se condição para o exercício da cidadania (GAGNON; IACOVINE, 2003 , p. 461). Ela é posta como fundamental para receber valores como a democracia, a liberdade de expressão e a igualdade entre homens e mulheres. Resta lembrar que a imposição do francês no Quebec não se restringiu aos imigrantes, afetando também os povos autóctones.

Segundo Salée (2003, p. 136-137), a imposição do francês não favoreceu o diálogo entre os povos indígenas e o governo da província, já que alguns deles já utilizavam a língua inglesa gerando desconfiança nessa relação. Para ele, "o estado quebequense praticaria uma política de 'dois pesos e duas medidas', proclamando sua soberania, seu direito fundamental de determinar seu futuro político e a indivisibilidade de seu território, sem reconhecer em contrapartida as mesmas prerrogativas às nações autóctones" (SALÉE, 2003, p. 134). A imposição da língua francesa se torna tão presente que o professor da Universidade de Victoria, de origem indígena kanien 'kehaka, Taiaiake Alfred (apud SALÉE, 2003, p. 132), chega a afirmar que a política quebequense é uma 
espécie de recolonização. Acrescentaríamos uma colonização linguística, que segundo Mariani (2004, p. 25 e 28),

supõe a imposição de ideias linguísticas vigentes e um imaginário colonizador enlaçando língua e nação em um projeto único [...] produzindo modificações em sistemas linguísticos que vinham se constituindo em separado, ou ainda, provoca reorganizações no funcionamento linguístico das línguas e rupturas em processos semânticos estabilizados. Colonização linguística resulta de um processo histórico de encontro entre pelo menos dois imaginários linguísticos constitutivos de povos culturalmente distintos - línguas com memórias, histórias e políticas de sentidos desiguais, em condições de produção tais que uma dessas línguas - chamada de língua colonizadora - visa impor-se sobre a(s) outra(s), colonizada(s).

Sob a ilusão de uma língua ou de duas línguas que pode(m) e deve(m) ser adquiridas para fazer parte da sociedade canadense, se encobre $(\mathrm{m})$ a(s) língua(s) colonizadora(s) que silencia $(\mathrm{m})$ outras línguas, outros sentidos possíveis, outras polissemias, outras falhas, outros deslizes, outras derivas, outras incompletudes que impediriam o real do discurso da diferença sob outras formas simbólicas, imaginárias e contraditórias.

Dessa maneira, na terra hospitaleira onde dois significantes, multiculturalismo e interculturalismo se confrontam, todos os imigrantes, das mais variadas culturas são bem-vindos, para desfrutar das iguais vantagens econômicas e sociais tão sonhadas por eles, desde que contribuam para a sociedade canadense, falem inglês e/ou francês e se assujeitem aos direitos humanos, isto é, desde que sejam canadenses.

Neste artigo, portanto, vimos que o discurso do multiculturalismo emerge também produzindo um deslocamento de políticas sobre a relação da diferença com o Estado e com a sociedade nacional canadense, de assimilação para integração. Mas ainda que se desloque trazendo outras práticas, algo se repete. Mantém-se a imposição dos valores ocidentais, mas, dessa vez, sustentados pelo discurso dos direitos humanos, sob a ilusão do sujeito universal que confere ao discurso do multiculturalismo um amplo poder de interpelação. Mantêm-se as muitas exigências para imigrar para o Canadá ou para se tornar cidadão do país, inclusive de ordem econômica. Mantém-se a ação da(s) língua(s) colonizadora(s), silenciando a variedade linguística e com ela outros efeitos de sentidos possíveis, de outras formações discursivas.

É possível, dessa maneira, identificar no discurso do multiculturalismo no Canadá, uma formação discursiva multiculturalista, dominante, que, na opacidade dos sentidos, aliada a outras, como a formação discursiva dos Direitos Humanos, acaba silenciando a diferença, ao significá-la como variedade e essa variedade como positiva ${ }^{21}$.

\footnotetext{
${ }^{21}$ Cabe acrescentar que esse sentido de multiculturalismo, como variedade e essa variedade como positiva, tornou-se um sentido dominante, atualmente em todo o mundo que se materializa inclusive, em alguns manuais de Sociologia e de Antropologia nos Estados Unidos e no Canadá (cf. HAVILAND et alii, 2011, e KOTTACK, 2013).
} 


\section{REFERÊNCIAS}

ALTHUSSER, Louis. Aparelhos ideológicos de Estado. Rio de Janeiro: Graal, 1985 [1970]. BARBOSA DA SILVA, D. "Uma terra hospitaleira de muitos imigrantes vindos do mundo todo": a emergência do discurso do multiculturalismo no Canadá. Interfaces Brasil/Canadá, v. 18, n. 1, 2018. Disponível https://periodicos.ufpel.edu.br/ojs2/index.php/interfaces/article/view/13087. Acesso em 20 jun. 2018.

. Dizer na cultura para dizer da diferença: o discurso da diversidade no discurso da política no Brasil. Tese. Doutorado em Estudos de Linguagem, Instituto de Letras, UFF, Niterói, 2016.

. A contradição discursiva no processo de universalização do sujeito de direitos humanos.

Entretextos, v. 13, n. 2, jul./dez. 2013a. Disponível em http://www.uel.br/revistas/uel/index.php/entretextos/article/view/15047. Acesso 15 ago. 2014.

Multiculturalismo no Canadá: uma análise do discurso do primeiro-ministro Pierre Trudeau. Anais do II Seminário Interno de Pesquisas do Laboratório Arquivos do Sujeito, UFF, Niterói, 2, 17-24, 2013b. Disponível em http://www.uff.br/las/periodicos/index.php/seminariointerno/article/view/35. Acesso 3/03/2014.

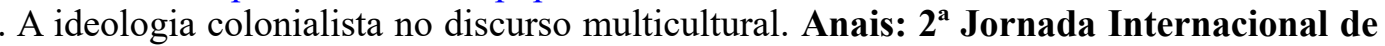

Estudos do Discurso e $1^{\circ}$ Encontro Internacional da Imagem em Discurso, 2012. Disponível em https://www.academia.edu/6162740/A ideologia_colonialista_no discurso_multicultural. Acesso em 8 fev. 2014.

CANADÁ. CIC (Department of Citizenship and Immigration), 2015. Disponível em: http://www.cic.gc.ca/english/. Acesso em 19 mar. 2014.

CANADÁ. Embaixada Canadense em Brasília. Sobre o Canadá. Informações Gerais sobre o Canadá, 2015. Disponível em http://www.canadainternational.gc.ca/brazilbresil/about apropos/overview-apercu.aspx?lang=por. Acesso em 15 jun. 2015.

Annual report on the operation of the Canadian Multiculturalism Act 2013-2014. Disponível em http://www.cic.gc.ca/english/pdf/pub/multi-ar-en-2014.pdf. Acesso 10 ago. 2015.

Annual report on the operation of the Canadian Multiculturalism Act 2012-2013. Disponível em http://www.cic.gc.ca/english/pdf/pub/multi-ann-report e.pdf. Acesso 10 ago. 2015.

Citizenship and Immigration Canada. Determine your elegibility - Citizenship, 2012. Disponível em http://www.cic.gc.ca/english/citizenship/become-eligibility.asp. Acesso em 03 dez. 2012.

. Discover Canada: The Rights and Responsibilities of Citizenship, 2012. Disponível em http://www.cic.gc.ca/english/pdf/pub/discover.pdf. Acesso em 02 nov. 2012.

Annual report on the operation of the Canadian Multiculturalism Act 2011-2012. Disponível em http://www.cic.gc.ca/english/pdf/pub/multi-report2012.pdf. Acesso 10 ago. 2015. Annual report on the operation of the Canadian Multiculturalism Act 2010-2011. Disponível em http://www.cic.gc.ca/english/pdf/pub/multi-report2011.pdf. Acesso 02 nov. 2012. Annual report on the operation of the Canadian Multiculturalism Act 2008-2009.

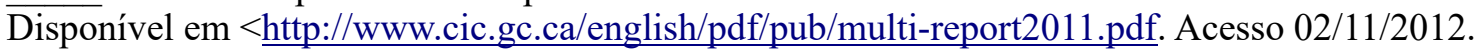

. Canadian Multiculturalism Act, de 21 de julho de 1988. An Act for the preservation and enhancement of multiculturalism in Canada. Disponível em http://lawslois.justice.gc.ca/eng/acts/c-18.7/. Acesso em 15 nov. 2012.

. Immigration Act, 1976. Disponível em http://www.pier21.ca/research/immigrationhistory/immigration-act-1976. Acesso em 17 jun. 2015.

CANADÁ. Royal Commission on Bilingualism and Biculturalism, 1969. Disponível em www.canadahistory.com/sections/documents/documents.html. Acesso em 18 fev. 2014.

CAVALCANTI, L.; SIMÕES, G. Assimilacionismo X multiculturalismo: reflexões teóricas sobre os modelos de recepção dos imigrantes. Esferas, n. 3, jul./dez. 2013. Disponível em http://portalrevistas.ucb.br/index.php/esf/article/view/5129. Acesso em 15 set. 2015.

COLLINS Cobuild English Grammar. Londres: HarperCollins Publishers, 1994.

ESTEBAN, V.; LÓPEZ-SALA, A. Em torno al mosaico canadiense. Una reflexión sobre la gestión política de la inmigración en Canadá. ARBOR [Ciencia, Pensamiento y Cultura], Madrid. v. 186, n. 744, jul.-ago., $2010 . \quad$ Disponível em http://arbor.revistas.csic.es/index.php/arbor/article/view/1216/1221. Acesso em 15 set. 2015. 
KYMLICKA, W. Multiculturalismo: o sucesso, o fracasso e o futuro. Interfaces Brasil/Canadá, v. 14, $14.2014 .218, \quad$ Disponível http://www.revistas.unilasalle.edu.br/index.php/interfaces/article/view/1576. Acesso 15 set. 2015.

GAGNON, A.-G.; IACOVINO, R. O interculturalismo: expandindo as fronteiras da cidadania. Em: GAGNON, A.-G. (Org.). Quebec: Estado e sociedade. Porto Alegre: Ed. da UFRGS, 2003. MARIANI, Bethania. Colonização Linguística. Campinas: Pontes Editores, 2004.

OLIVEIRA, João Pacheco (Org.). A viagem da volta: etnicidade, política e reelaboração cultural no Nordeste Indígena. Rio de Janeiro: ContraCapa; LACED, 2004.

OLIVERAS, Neus. El multiculturalismo. In: MITJANS, Esther; CASTELLÀ, Josep (Coords.). Canadá: introducción al sistema político y jurídico. Barcelona: Universitat de Barcelona, 2001. ORLANDI, E.P. Análise de discurso: princípios e procedimentos. Campinas: Pontes, 2007.

. Espaços linguísticos e seus desafios: convergências e divergências. Rua, n. 18, v. 2, 2012b. Disponível em http://www.labeurb.unicamp.br/rua/pages/home/capaArtigo.rua?id=131. Acesso em 28 abr. 2013.

PÊCHEUX, Michel. Análise de Discurso: Michel Pêcheux. Campinas: Pontes, 2011.

. Semântica e Discurso. Campinas: Unicamp, 2009 [1975].

QUEBEC. Conhecer, respeitar, partilhar: valores em comum da sociedade quebequense, 2009. Disponível em https://www.immigration-quebec.gouv.qc.ca/publications/pt/DepliantValeursCommunes-PT.pdf. Acesso em 10 ago. 2015.

RATTANSI, Ali. Multiculturalism: a very short introduction. Oxford: OUP, 2011.

SALÉE, Daniel. O Estado quebequense e a questão autóctone. Em: GAGNON, A.-G. (Org.). Quebec: Estado e sociedade. Porto Alegre: Editora da UFRGS, 2003.

SWAN, M. Practical English Usage. Oxford: OUP, 2002.

TRUDEAU, P.E. Announcement of Implementation of Policy of Multiculturalism within Bilingual Framework. Ottawa: Ottawa House of Commons, 1971. Disponível em http://www.canadahistory.com/sections/documents/Primeministers/trudeau/docsonmulticulturali sm.htm. Acesso em 02 nov. 2012.

Artigo recebido em: março de 2018.

Aprovado e revisado em: julho de 2018.

Publicado em: dezembro de 2018.

\section{Para citar este texto:}

BARBOSA DA SILVA, Diego. O discurso canadense do multiculturalismo no discurso dos direitos humanos: integrar ou assimilar? Entremeios [Revista de Estudos do Discurso, ISSN 2179-3514, on-line, www.entremeios.inf.br], Seção Estudos, Programa de Pós-Graduação em Ciências da Linguagem (PPGCL), Universidade do Vale do Sapucaí (UNIVÁS), Pouso Alegre (MG), vol. 17, p. 163-174, jul. - dez. 2018.

DOI: http://dx.doi.org/10.20337/ISSN2179-3514revistaENTREMEIOSvol17pagina163a174 